EPiC Series in Language and Linguistics
Volume 2, 2017, Pages 181-190
Professional and Academic Discourse:
an Interdisciplinary Perspective

\title{
The Interpretation of Negated Quantifiers in Spanish
}

\author{
Tania Barberán Recalde \\ University of the Basque Country, Spain \\ mariatania.barberan@ehu.eus
}

\begin{abstract}
Children tend to accept weak Quantifiers (Q) in contexts where strong ones hold, failing to generate Scalar Implicatures (SI) (Noveck, 2001/2004). The interpretation of a negated sentence containing a Q requires: (i) pragmatic knowledge to derive the SI and (ii) syntactic knowledge to determine the scope of negation (Neg). Uttering any of the sentences in $1(\mathrm{a}, \mathrm{b})$ in a context where zero students attended the talk is underinformative, because the stronger Q none should be employed in order to be as informative as possible (Grice, 1975/1989).

(1) a. NOT ALL the students attended the talk

b. ALL the students did NOT attend the talk

The fact that Neg occupies a different position in (1a) with respect to (1b) can have an influence on the interpretation of the sentence. While (1a) in English is interpreted by adults as 'NOT ALL'=some, (1b) can be interpreted as 'ALL NOT'=some or 'ALL NOT'=none. Following the "Observation of isomorphism" (Musolino, 1998), children tend to obtain isomorphic-readings, so they are predicted to interpret 'NOT ALL'=some and 'ALL NOT'=none. Based on Katsos et al.'s (2012) materials, a Picture Selection Task (PST) was conducted with 5-year-old monolingual-L1Spanish $(\mathrm{n}=25)$ children, as well as with adult native speakers of Spanish $(n=17)$, to test their interpretation of 'all not' for Spanish todos no (Q-Neg) and of 'not all' for no todos (Neg-Q). Participants had to select one of two pictures presented on a screen, after hearing an utterance containing Q-Neg or Neg-Q. The pictures represented a none-context (where zero of five items were in the boxes) and a some-context (where two of five items were in the boxes). Results from the PST showed that Spanish children chose the none-context for Q-Neg in 73\% of cases (isomorphic-readings). For Neg-Q the results were not so homogeneous, since Spanish children chose the some-context in 55\% of cases. Spanish adults chose the some-context for Neg-Q in 95\% of cases, and for Q-Neg the nonecontext in $83 \%$ of cases. While Spanish children and adults prefer the none-reading in Q-Neg, adults' preference for the some-reading in Neg-Q contrasts with children's response in that condition. This response pattern raises new questions regarding children's preference for isomorphic-readings and leads to interesting predictions for the acquisition of negated Qs in Spanish.
\end{abstract}




\section{Introduction}

The issue of the interaction between quantifiers and negation in L1 acquisition has been a quite relevant theoretical topic since the second half of the nineties (Musolino, 1998; Lidz \& Musolino 2002; Musolino \& Lidz, 2006; Moscati \& Gualmini 2008; a.o.). Taking into account that little research has been done on this topic with a language such as Spanish, this study aims to test (i) whether 5-year-old L1Spanish children are sensitive to the different scope relations between QNeg/Neg-Q, (ii) whether there are differences between L1Spanish children and adults regarding the interpretation of those structures, and (iii) whether our results can be accounted for by the "Observation of Isomorphism” described in the literature (Musolino, 1998; Musolino, Crain \& Thornton 2000). The main research question that many authors have addressed is if children can access both the isomorphic (i.e. surface scope) and the non-isomorphic (i.e. non-surface scope) interpretations of sentences which contain a quantifier plus a negative operator, or if they can only access the isomorphic interpretation of those types of sentences. In fact, Musolino (1998; p. 112) observed that 4- and 5-year-old children can only access the isomorphic interpretation of sentences like (2).

(2) Every horse didn't jump over the fence.

(3) a. $\forall \mathrm{x}$ [horse (x) $\rightarrow \neg$ jump over the fence (x)]

'For every horse, it is such that it didn't jump over the fence' $\rightarrow$ 'none did'

b. $\neg \forall \mathrm{x}$ [horse $(\mathrm{x}) \rightarrow$ jump over the fence $(\mathrm{x})$ ]

'It is not the case that every horse jumped over the fence' $\rightarrow$ 'not all did'

The sentence in (2) is ambiguous between a 'none' (3a) and a 'not all' (3b) reading. More specifically, (3a) corresponds to an isomorphic interpretation of (2) (where the quantifier takes scope over the negative operator), and (3b) corresponds to a non-isomorphic interpretation of (2) (where the negative operator takes scope over the quantifier). From the results obtained in this study, Musolino (1998) (and afterwards, Musolino, Crain \& Thornton, 2000) proposed the Observation of Isomorphism described in (4):

\section{(4) Observation of Isomorphism}

Children's semantic scope coincides with overt syntactic scope.

Musolino et al. (2000) claimed that children's semantic interpretation of sentences like (2) corresponded to the syntactic reading they obtained, which was usually based on the Surface Scope (SS) structure of the sentence in question (i.e. isomorphic-readings).

Lidz and Musolino (2002) discovered afterwards that 4-year-old children, native speakers of English (a head-initial language) and Kannada (a head-final language, spoken in the state of Karnataka, in the southeast of India, and whose canonical word order is SOV), relied on the ccommand information given by the SS structure when having to interpret a sentence with a negative operator plus a numeral quantifier.

It is important to highlight the fact that while in English the negative operator precedes the numeral quantifier linearly as in (5), in Kannada it is the other way around as can be observed in (6) (examples taken from Lidz and Musolino, 2002).

(5) I didn't read two books

(6) (4) naanu eraDu pustaka ood-al-illa

I-nom two book read-inf-neg

'I didn't read two books'

The fact that in both languages (English and Kannada) children obtain the same interpretation (Neg - Q) suggests that 4-year-old children do not rely on the lineal word order of sentences, but they 
do rely on the c-command information provided by the given sentence (see example (7), taken from Lidz and Musolino, 2002), because if they were relying on the lineal word order of the sentence, the native speakers of Kannada would obtain just the opposite interpretation (Q - Neg). Lidz and Musolino (2002) consequently affirmed that 4-year-old children rely specifically on the c-command information provided by the syntactic structure of the sentence in question. ${ }^{*}$

(7)

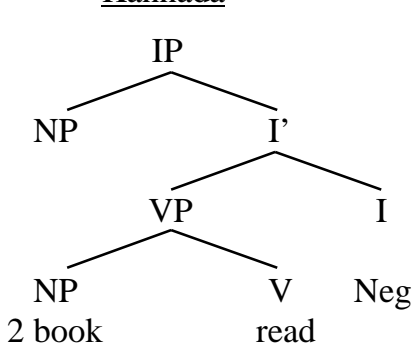

English

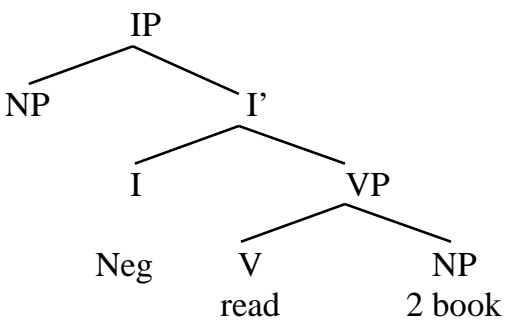

In a subsequent study, Musolino and Lidz (2006) discovered that with an appropriate linguistic context, 5-year-old children could access more readily to the non-isomorphic readings of sentences like (5) and (6). However, they claimed that children's cognitive resources to derive non-isomorphic interpretations are much more fragile than those of adults.

Another study in line with Lidz \& Musolino (2002) is the one conducted by Gualmini \& Crain (2005). These authors found out that 4/5-year-old children resorted to syntactic principles (and specifically to c-command information), in order to know if the particle or was conjunctive or disjunctive in a series of negative sentences. In fact, when the negative operator has scope over or, this particle is conjunctive, but when the negative operator does not have scope over or, this particle is disjunctive (this is known as "De Morgan's Law"). Gualmini \& Crain (2005) uphold, therefore, that the syntactic structure (and specifically the c-command information) is the main source of interpretation for $4 / 5$-year-old children.

Other studies on children's comprehension of the interaction between quantifiers and negation can also be found in the literature on first language acquisition (see Roeper and Matthei, 1975; BoyssonBardies, 1977; Drozd and Philip 1993, O'Leary \& Crain, 1994; Thornton, 1995; Krämer, 2000, Katsos et al., 2012; a.o.).

\section{Negated Quantifiers in Spanish}

It has been suggested that in Spanish the Negative Phrase (NegP) occupies an external position to the Inflectional Phrase (IP) and that the inflection (Infl) does not adjoin to Neg (see Laka, 1990 and Etxepare \& Uribe-Etxebarria, 2011). Thus, a sentence like (8), in which Neg linearly precedes the universal Q todas ‘all', would obtain the structure represented in (9):

\footnotetext{
* The left-branching structure observed in (7) for Kannada corresponds to its head-final nature, while the right-branching structure of English corresponds to its head-initial nature.
} 
(8) No todas las manzanas están en las cajas

(9)

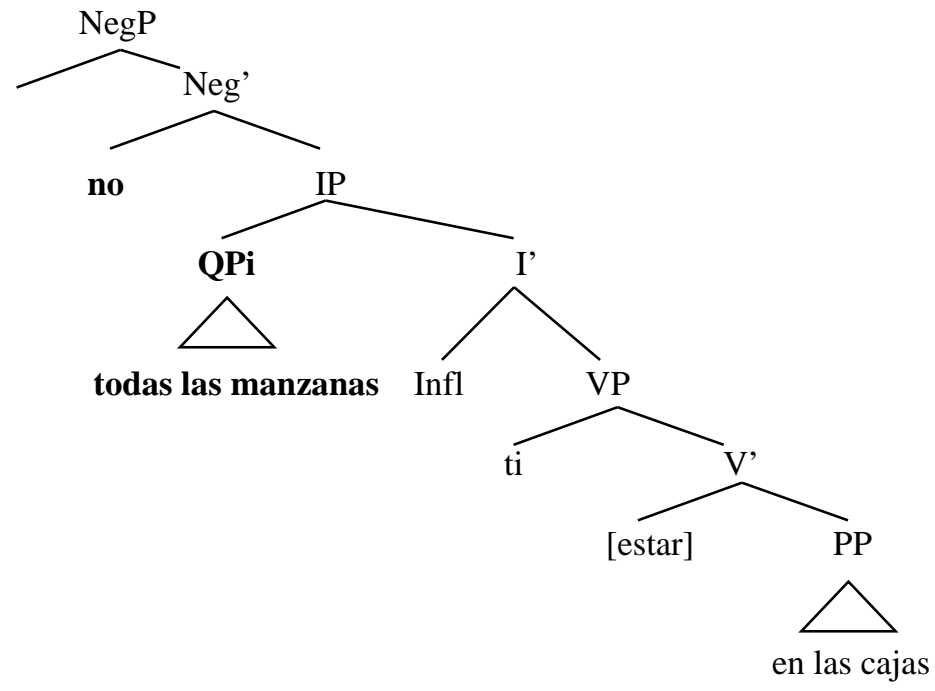

In the structure represented in (9), it can be observed that Neg c-commands the QP todas las manzanas, but not the other way around.

If the Observation of Isomorphism (Musolino 1998; Musolino, Crain \& Thornton 2000) is right, and "children's semantic scope coincides with overt syntactic scope", our prediction would be the following one:

Prediction 1: L1Spanish children will interpret a sentence like "No todas las manzanas están en las cajas" with Neg having scope over the QP todas las manzanas, thus they will derive a some-reading.

A sentence like (10), in which the universal Q todas 'all' linearly precedes Neg, would obtain the structure in (11):

(10) Todas las manzanas no están en las cajas

(11)

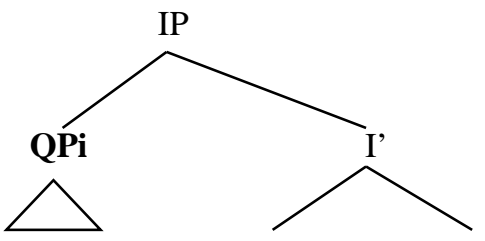

todas las manzanas

Infl
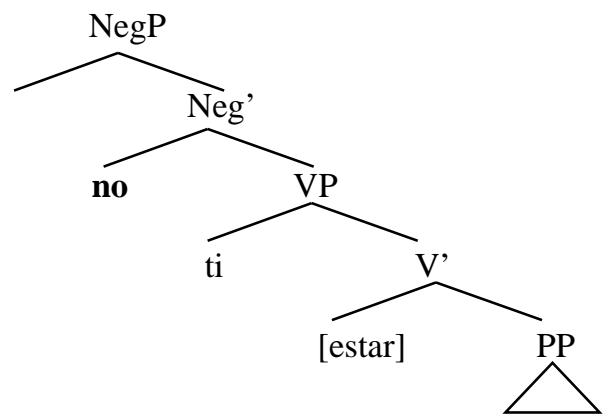

en las cajas

In the structure represented in (11), it can be observed that the QP todas las manzanas ccommands Neg, but not the other way around. 
Based on the Observation of Isomorphism, our second prediction would be the following one:

Prediction 2: L1Spanish children will interpret a sentence like "Todas las manzanas no están en las cajas” with the QP todas las manzanas having scope over Neg, thus they will derive a none-reading.

\section{Study}

The present study aims to explore how L1Spanish 5-year-old children and adults interpret no todos 'not all' (Neg-Q) and todos no 'all not' (Q-Neg), i.e. either they obtain a some-reading or a nonereading. Let us recall both the research questions and the predictions:

\subsection{Research Questions}

(i) Are 5-year-old L1Spanish children sensitive to the different scope relations between QNeg/Neg-Q?

(ii) Are there differences between L1Spanish children and adults regarding the interpretation of those structures?

(iii) Can our results be accounted for by the "Observation of Isomorphism" described in the literature (Musolino, 1998; Musolino, Crain \& Thornton 2000)?

\subsection{Predictions}

If the "Observation of Isomorphism" (Musolino, 1998; Musolino, Crain \& Thornton 2000) is right, we predict that:

(i) L1Spanish children will interpret a sentence like "No todas las manzanas están en las cajas" with Neg having scope over the QP todas las manzanas, thus they will derive a some-reading. $\rightarrow$ If $\mathrm{Neg}>\mathrm{Q}=$ some-reading.

(ii) L1Spanish children will interpret a sentence like "Todas las manzanas no están en las cajas” with the QP todas las manzanas having scope over Neg, thus they will derive a none-reading. $\rightarrow$ If $\mathrm{Q}>\mathrm{Neg}=$ none-reading.

\subsection{Method}

A Picture Selection Task (PST) was developed, based on the materials of Katsos et al. (2012). Participants were asked to choose one of two pictures presented on a screen, after hearing an utterance produced by a puppet, i.e. The Cavegirl. It was a forced-choice task, thus participants were asked to choose the picture which best suited each utterance. The two pictures presented on each slide represented two different contexts (12a,b):

(12) a. '0/5 context': 0 out of 5 objects are inside the boxes (interpreted as a none-reading').

b. '2/5 context': 2 out of 5 objects are inside the boxes (interpreted as a some-reading).

12 utterances were produced for the quantifier no todos 'not all', and another 12 utterances for the quantifier todos no 'all not'. With each quantifier, 6 utterances were produced in a visual-setting where the ' $0 / 5$ context' was on the left-side and the ' $2 / 5$ context' on the right-side of the screen (see Figure 1), and the other 6 utterances were produced in a visual-setting where the ' $2 / 5$ context' was on the left-side and the ' $0 / 5$ context' on the right-side of the screen (see Figure 2). 


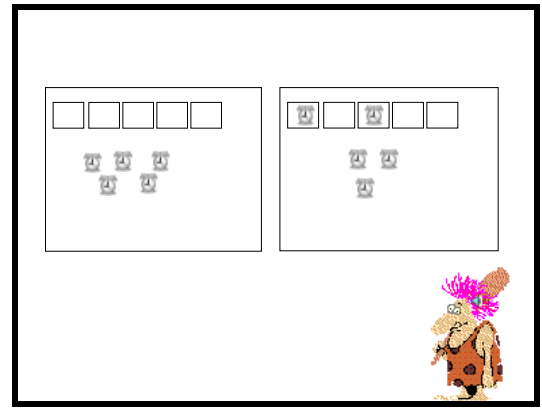

Figure 1

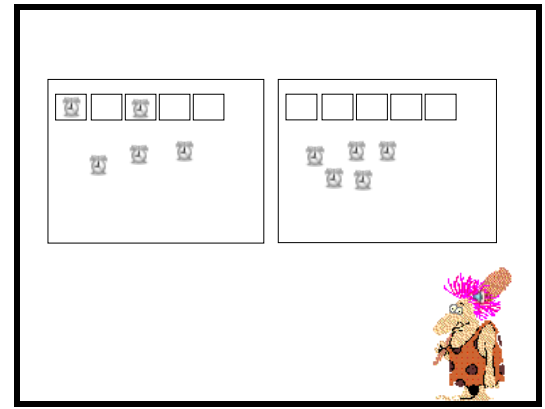

Figure 2

The utterances produced for the quantifier no todos 'not all' were like the sentence in (13), and the ones produced for the quantifier todos no 'all not' were like the sentence in (14):

(13) NO TODAS las manzanas están en las cajas.

Not all the apples are in the boxes

'Not all the apples are in the boxes'

(14) TODAS las manzanas NO están en las cajas.

All the apples not are in the boxes

'All the apples are not in the boxes'

Apart from the 24 test items (12 for each quantifier), there were 5 training items with numerals (at the beginning of the experiment), 8 distractors and 24 fillers (61 slides in total). Within the fillers, there were 12 items which tested the quantifier algunos 'some', and other 12 which tested the quantifier ninguno 'none'.

As with the test items, both with algunos 'some' and with ninguno 'none', 6 fillers were produced in a visual-setting where the ' $0 / 5$ context' was on the left-side and the ' $2 / 5$ context' on the right-side of the screen, and the other 6 fillers were produced in a visual-setting where the ' $2 / 5$ context' was on the left-side and the ' $0 / 5$ context' on the right-side of the screen.

In Table 1 the experimental items, their linear order and the possible chosen pictures (from the different picture pairs), together with their scope option - Surface Scope Reading (SSR) vs. Non Surface Scope Reading (NSSR) - and the interpretation is presented.

\begin{tabular}{|c|c|c|c|c|c|}
\hline $\begin{array}{l}\text { Linear } \\
\text { Order }\end{array}$ & Exp. Item & $\begin{array}{l}\text { Chosen } \\
\text { Picture }\end{array}$ & \multicolumn{2}{|c|}{ Scope Option } & Interpretation \\
\hline \multirow{2}{*}{ Q-Neg } & \multirow{2}{*}{$\begin{array}{l}\text { todos...no } \\
\text { 'all not' }\end{array}$} & $0 / 5$ & SSR & $\mathrm{Q}>\mathrm{Neg}$ & $\forall \neg$ 'none' \\
\hline & & $2 / 5$ & NSSR & Neg $>$ Q & $\neg \forall$ 'some' \\
\hline \multirow{2}{*}{ Neg-Q } & \multirow{2}{*}{$\begin{array}{l}\text { no todos } \\
\text { 'not all' }\end{array}$} & $0 / 5$ & NSSR & $\mathrm{Q}>\mathrm{Neg}$ & $\forall \neg$ 'none' \\
\hline & & $2 / 5$ & SSR & Neg $>$ Q & $\neg \forall$ 'some' \\
\hline
\end{tabular}

Table 1: Possible answers in the PST 


\subsection{Participants}

Data from 25 L1Spanish 5/6-year-old (mean age: 5;7) children was collected in a school located in Pamplona (Navarre). These children are monolingual speakers of Spanish and they communicate in Spanish both at home and at school. With respect to second languages, they have just started studying English at school. In addition, 17 adult native speakers of Spanish were tested as well.

\subsection{Results}

In Figure 3 it can be observed that for todos no 'all not' (Q-Neg) L1Spanish children choose the 0/5 picture (none-reading) in a 73\% of cases (a clear preference for Surface Scope readings), but when the reversed order between the quantifier and the negative operator is tested (Neg-Q) the results are not so homogeneous, since for no todos 'not all' L1Spanish children choose the 2/5 picture in a 55\% of cases and the $0 / 5$ picture in a $45 \%$ of cases (no clear preference for one picture over the other ).

L1Spanish adults chose the 2/5 picture (some-reading) for Neg-Q in 95\% of cases, and for Q-Neg the $0 / 5$ picture (none-reading) in $83 \%$ of cases. Thus, while Spanish children and adults prefer the none-reading in Q-Neg, adults' preference for the some-reading in Neg-Q contrasts with children's response in that condition.

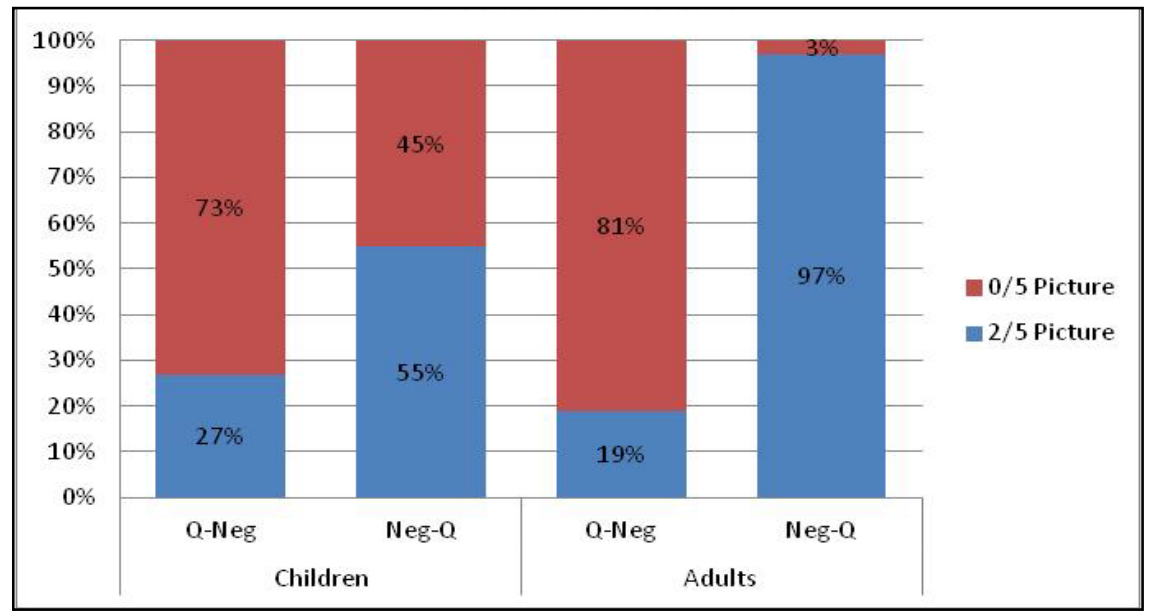

Figure 3: Mean of picture choice rates bv children and adults with O-Neg and Neg-O

If children's percentages of selection of the 2/5 picture with todos no 'all not' and no todos 'not all' are analyzed in detail (i.e. individual scores), the following results can be observed (see Figure 4):

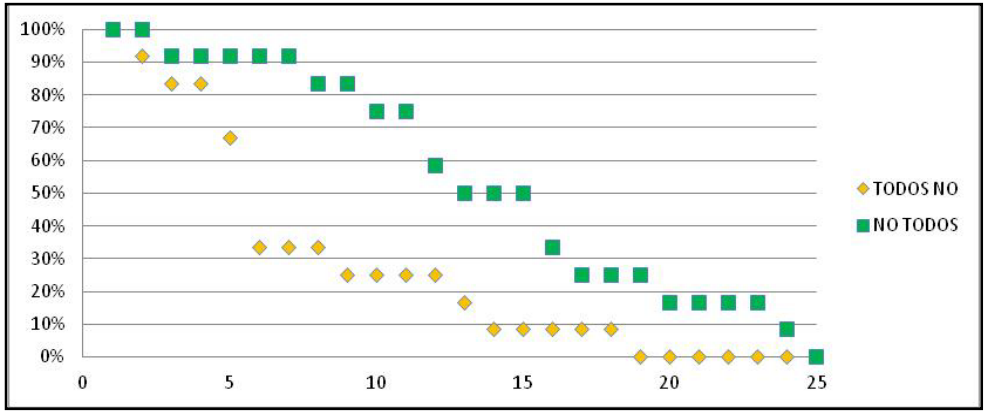

Figure 4: Children's choice rates of picture 2/5 with Q-Neg and Neg-Q 
In Figure 4 it can be observed that while the majority of the children choose the $0 / 5$ picture for todos no 'all not' (none-reading), they show no clear preference for one reading over the other with no todos 'not all' (55\% of 2/5 picture choice) and a high interindividual variation is found (multimodal distribution).

\section{Discussion}

The research questions of the study were the following ones:

(i) Are 5-year-old L1Spanish children sensitive to the different scope relations between QNeg/Neg-Q?

(ii) Are there differences between L1Spanish children and adults regarding the interpretation of those structures?

(iii) Can our results be accounted for by the "Isomorphism Effect" described in the literature (Musolino, 1998; Musolino, Crain \& Thornton 2000)?

With respect to research question (i), it has been observed that 5-year-old L1Spanish children are indeed sensitive to the different scope relations between Q-Neg/Neg-Q. In fact, while they obtain a none-reading when interpreting todos no 'all not' (Q-Neg), they show no preference for one reading over the other with the opposite order Neg-Q. Thus, it can be concluded that the 5-year-old L1Spanish children tested in the present experiment are sensitive to the different position of the negative operator with respect to the universal quantifier.

Regarding research question (ii), the results obtained in this study show that there are differences between L1Spanish children and adults with the Neg-Q condition. When the order Q-Neg is tested (todos no 'all not'), both L1Spanish children and adults obtain a none-reading. However, when the reversed order Neg-Q is tested (no todos 'not all'), while adults obtain a some-reading, we have observed that children show no preference for one picture over the other (they display a multimodal distribution).

With regard to research question (iii), the Observation of Isomorphism (Musolino 1998; Musolino, Crain \& Thornton 2000) has not been fully attested in this study. Based on this Observation, our predictions were that (a) L1Spanish children would obtain a some-reading when interpreting no todos 'not all', and that (b) they would obtain a none-reading when interpreting todos no 'all not', that is, they would obtain isomorphic readings. While prediction (b) has been satisfied, this is not the case for prediction (a), since 13 (out of 25) children obtain a none-reading with no todos 'not all' (Neg-Q), which is a non-isomorphic reading in this case. Therefore, the results obtained in this study are only partially accounted by the Observation of Isomorphism (i.e. when the order Q-Neg is tested).

The fact that L1Spanish children seem to have access to non-isomorphic readings when the order Neg-Q is tested (no todos 'not all') goes in line with Musolino and Lidz (2006), who discovered that with an appropriate linguistic context, 5-year-old children could access more readily to nonisomorphic readings. However, a further study with a bigger population should be conducted (and maybe with a different methodology), in order to conclude that 5/6-year-old children can actually access non-isomorphic readings.

Apart from the data obtained with children, another interesting fact about the results obtained in the present study is that L1Spanish adults obtain isomorphic readings with both Q-Neg and Neg-Q orders, being in this way "more isomorphic" than children. It can be the case that the utterances tested in Spanish are not ambiguous for adults (no todos 'not all' = some-reading, and todos no 'all not' = none-reading), or it can be a task-effect by which adults are unconsciously assigning one reading to an order (Q-Neg) and the other reading to the other order (Neg-Q) in a consistent way. 
For this purpose a follow-up study could be conducted in which adults have the option to select none of the two pictures presented.

In any case, the two main contributions of the present paper for the study of the interaction between universal quantifiers and negation are that (i) half (13 out of 25) of the L1Spanish children obtain non-isomorphic readings when the order Neg-Q is tested, and that (ii) L1Spanish adults obtain isomorphic readings with both orders (Neg-Q and Q-Neg).

Both response patterns raise new questions regarding children's preference for isomorphicreadings and lead to interesting predictions for the acquisition as well as the adult interpretation of negated universal quantifiers in Spanish.

\section{Conclusion}

The results obtained in the present study reveal that (i) 5-year-old L1Spanish children are sensitive to the different scope relations between Q-Neg/Neg-Q, that (ii) there are differences between L1Spanish children and adults when the Neg-Q condition is tested, and that (iii) the Observation of Isomorphism (Musolino 1998; Musolino, Crain \& Thornton 2000) has only been partially attested, since L1Spanish children can access non-isomorphic readings when the order Neg-Q is tested.

\section{References}

Drozd, K. and Philip, W. (1993). Event quantification in preschoolers' comprehension of negation. In E.V. Clark (Ed.), Proceedings of the 24th Annual Child Language Research Forum. Stanford, CA: Center for the Study of Language and Information.

Etxepare, R. \& Uribe-Etxebarria, M. (2011). Foco y negación de constituyentes en español. In V. Escandell, M. Leonetti and C. Sanchez (eds), 60 problemas de gramática. Dedicados a Ignacio Bosque. Madrid: Akal. 235-241. ISBN: 9788446034278.

Grice, H. P. (1975). Logic and conversation. In Cole, P., and J.L. Morgan (Eds.), Speech Acts. New York: Academic Press, 41-58.

Grice, H. P. (1989). Studies in the way of words. Cambridge, MA: Harvard University Press.

Gualmini, A., \& Crain, S. (2005). The structure of children's linguistic knowledge. Linguistic Inquiry, 36(3), 463-674.

Katsos N. et al (2012). The acquisition of quantification across languages: Some predictions. In Proceedings of the 26th Boston University Conference on Language Development. Alia K. Biller, Esther Y. Chung, and Amelia Kimball (Eds.), 258-268. Cascadilla Press, Somerville, MA.

Krämer, I. (2000). Interpreting Indefinites: An experimental study of children's language comprehension. Doctoral dissertation, MPI Series in Psycholinguistics.

Laka, I. (1990). Negation in Syntax: On the Nature of Functional Categories and Projections. Doctoral dissertation, MIT, Dept. of Linguistics and Philosophy.

Lidz J. \& Musolino J. (2002). Children's command of quantification. Cognition, 84 (2), 113-154.

Moscati, V., \& Gualmini, A. (2008). More Facts that Isomorphism Cannot Explain. In T. Friedman and M. Gibson (Eds.), Proceedings of Semantics and Linguistic Theory 17 (SALT XVII) (pp. 202-209). Ithaca, NY: Cornell University.

Musolino, J. (1998). Universal Grammar and the acquisition of semantic knowledge: an experimental investigation of quantifier-negation interaction in English. Doctoral Dissertation, University of Maryland.

Musolino, J., S. Crain and R. Thornton (2000). Navigating Negative Quantificational Space. Linguistics, 38-1. 
Musolino, J. and Lidz, J. (2006). Why Children aren't universally successful with Quantification. Linguistics, 44(4), 817-852.

Noveck, Ira (2001). When the children are more logical than adults: Experimental investigations of scalar implicatures. Cognition, 86 (3), 253-282.

Noveck, Ira (2004). Pragmatic inferences related to logical terms. Noveck, Ira \& Sperber, Dan (eds.): Experimental Pragmatics. Palgrave: Basingstoke, 301-335.

O’Leary, C. and Crain, S. (1994). Negative polarity items (a positive result) positive polarity items (a negative result). Paper presented at the 1994 Boston University Conference on Language Development.

Roeper, T. and E. Matthei (1975). On the acquisition of all and some. Papers and Reports on Child Language Development 9. Stanford: Stanford University Press.

Thornton, R. (1995). Children's negative questions: a production/comprehension asymmetry. In Proceedings of ESCOL, J. Fuller, H. Han, and D. Parkinson (Eds.). Ithica, NY: Cornell University. 